\title{
Endoscopic colonic decompression
}

\author{
NORMAN E MARCON, MD, FRCPC
}

\begin{abstract}
Colonic pseudo-obstruction, or Ogilvie's syndrome, is characterized by marked distension of the large intestine in the absence of mechanical obstruction. Etiology is unknown. Left untreated, it may lead to perforation with a mortality of $46 \%$. Reversible causes such as electrolyte imbalance, anticholinergic drugs, analgesics, steroids or hypothyroidism should be excluded. Early recognition of pseudo-obstruction with institution of supportive means followed by colonoscopic decompression with tube placement should be successful in all cases. Can J Gastroenterol 1990;4(9):542-545
\end{abstract}

Key Words: Colonoscopy, Pseudo-obstruction, Tube decompression

\section{La décompression du côlon par endoscopie}

RESUME: La pseudo-occlusion du côlon, aussi appelée syndrome d'Ogilvie, se caractérise par la distension marquée du gros intestin en l'absence de toute obstruction mécanique. Non traitée, cette affection d'étiologie inconnue peut entraîner une perforation accompagnée d'un taux de mortalité de $46 \%$. Il est nécessaire d'exclure toutes causes réversibles - déséquilibre électrolytique, anticholinergiques, analgésiques, stéroïdes ou hyperthyroïdisme. Le diagnostic précoce de pseudo-obstruction et l'institution de moyens de soutien suivis par la décompression du côlon par endoscopie devraient résoudre tous les cas.

$\mathrm{C}$ OLONIC PSEUDO-OBSTRUCTION, OR Ogilvie's syndrome (1), is characterized by marked distension of the large intestine in the absence of mechanical obstruction. It is a form of colonic ileus that, left untreated, may lead to perforation of the right colon with a mortality rate as high as $46 \%$ (2). Urgent surgical decompression with cecostomy is reported to have a mortality rate of 12 to $20 \%$ (3). Over a decade ago these patients required surgical treatment.
Endoscopic decompression will now become the treatment of choice.

The etiology of this syndrome is unknown. Ogilvie (1) in 1948 reported a patient with colonic distension who had invasive carcinoma at the root of the mesentery involving the prevertebral ganglion. He believed that this invasion resulted in an autonomic imbalance leading to distension. This concept is still acceptable. These patients are unwell with major systemic illnesses, sep- sis, recent trauma or operation. Many come from intensive care units.

\section{DIAGNOSIS}

Typically a sick or injured patient is noted to have developed progressive abdominal distension. This is often associated with diminished bowel sounds and, depending on the degree of distension, some tenderness. There may or may not be diarrhea. In contrast to mechanical obstruction, vomiting is uncommon. Significant peritoneal signs could imply that perforation is impending or has occurred. Confirmation of the diagnosis of pseudo-obstruction requires abdominal $x$-rays in the supine and lateral positions (4).

Controversy exists as to what cecal measurement is most critical. A cecal diameter of $9 \mathrm{~cm}$ or less is not likely to lead to perforation. Most agree that a diameter of $12 \mathrm{~cm}$ or more requires close observation (5). With this degree of bowel distension, the physician is obliged to rule out a mechanical lesion. Concern over obstruction can be eliminated either endoscopically or radiologically with an enema using a water-soluble contrast media such as Hypaque (Winthrop). The mechanical causes could be distal obstruction or missed cecal volvulus (6). The watersoluble contrast enema may have an additional beneficial effect because of its osmotic character, and may aid in the emptying of the distal colon. 
TABLE 1

Conservative management of pseudo-obstruction of the colon

Rule out mechanical cause

(Gastrografin enema)

Correct electrolyte and metabolic or

septic problems

Stop analgesics

Nasogastric suction

Rectal tube

Cleansing enema

Frequent turning of patient

The usual approach is to follow the patient's abdominal signs closely and repeat the films in 6 to $8 \mathrm{~h}$, depending on the clinical situation, and comparing cecal diameters. Reversible causes, such as electrolyte imbalance, anticholinergic drugs, analgesics, steroids or hypothyroidism should be excluded. Analgesics are thought to be the most common reversible cause. In a review of the literature, the number of cases that resolve with conservative management varied from 40 to $96 \%$ (7). In the latter study, most cases resolved within two days. The clinician must decide whether to proceed to endoscopic decompression rather then wait an inordinate period of time and risk perforation, if there is no resolution.

\section{SUPPORTIVE THERAPY}

In some patients the distension will resolve by discontinuation of medication and general supportive measures such as hydration, enemas, and a rectal tube (Table 1). The passage of a nasogastric tube and withholding oral intake are helpful. Frequent turning of the patient to the prone position allows redistribution of colonic gas into the descending colon and allows easier evacuation.

\section{ENDOSCOPIC APPROACH}

The endoscopic approach was first reported in 1977 (8). Colonoscopic decompression is initially successful in the vast majority of cases. However, in a sizable proportion of patients varying from 20 to $60 \%$, there was recurrence of the pseudo-obstruction within a few hours to days (9-11). This would then necessitate a repeat colonoscopic decompression or operative decompression.
There are some concerns about the risks of colonoscopic attempts at decompression in an already distended and usually unprepared colon. Resultant perforation in many of these sick patients would be potentially more serious (11). However, the author's experience has supported the theory that endoscopy can be carried out safely and effectively in virtually all patients. There is no question that colonoscopy under these circumstances - with an ill patient and an unprepared bowel - is more difficult, takes longer and requires more care than routine colonoscopy. The use of frequent and large irrigations of tap water through the accessory channel may be necessary for visualization, and allows the cecum to be reached in virtually all cases. Only the smallest amounts of air are insufflated during the examination. Manual pressure by an assistant can also facilitate the expulsion of air. Success of decompression is confirmed by reduction of abdominal distension and cecal size seen on fluoroscopy.

The endoscopist should watch for evidence of mucosal ischemia, which is demonstrated by a dusky, hemorrhagic or ulcerated mucosa, usually in the right colon.

In the past, management of patients whose distension persisted despite endoscopy or soon recurred, required either repeat endoscopy or surgical decompression by cecostomy. The author believes that this mode of treatment is now unacceptable, and all patients with pseudo-obstruction who are treated by colonic decompression should have, at the time of endoscopy, a decompression tube placed in the right colon.

A number of techniques has been described which will accomplish this (Table 2).

Although fluoroscopy is not mandatory to reach the right colon, it is certainly helpful and necessary for monitoring tube placement. Ideally the patient should be endoscoped on a fluoroscopy table.

The author's initial technique was to use a two-channel colonoscope with a large channel (10F). When the endoscope reached the cecum, a Wilson-
TABLE 2

Colonoscopic methods of endoscopic decompression

Colonoscopy to right colon with

suction decompression

Colonoscopy to right colon with drop off' of decompression tube attached by long suture, two-channel endscope

Colonoscopy to right colon with large channel endoscope and passage of 10F nasobiliary tube through endoscope channel with pusher tube

Colonoscopy to right colon with regular' endoscope

Passage of sheathed guidewire Endoscope removed

Decompression tube passed over guidewire

Colonoscopy to right colon with long fenestrated tygon overtube

Cook $10 \mathrm{~F}$ nasobiliary catheter (Figure 1) with extra holes cut was pushed out over a flexible Teflon-coated sheathed guidewire $480 \mathrm{~cm}$ long. The catheter was pushed out by pusher tube as the endoscope was withdrawn. Although the author's first cases were performed under fluoroscopy (12), this tube can be placed without fluoroscopy. This is possible because the $10 \mathrm{~F}$ Wilson-Cook nasobiliary tube is sufficiently stiff that, as it is pushed out, there is little chance of it slipping back from the right colon as the endoscope is withdrawn. A colonoscope with a large $10 \mathrm{~F}$ channel is required.

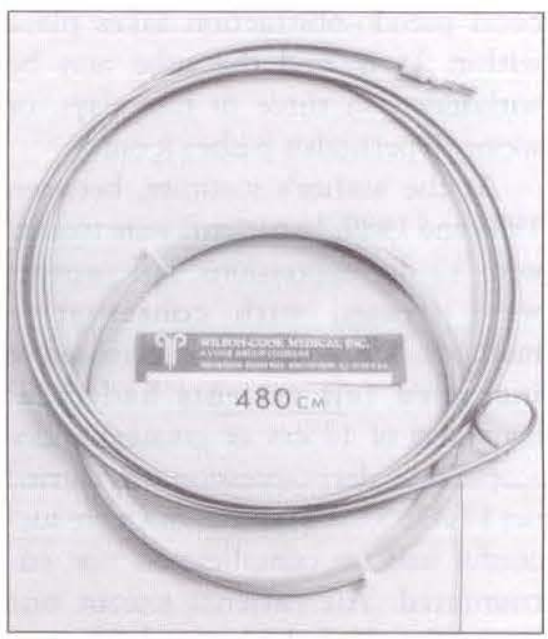

Figure 1) Wilson-Cook IOF nasobiliary tube with $480 \mathrm{~cm}$ guidewire 
Using a standard colonoscope with a $2.8 \mathrm{~mm}$ single accessory channel, the following procedure may be carried out. On reaching the cecum, the guidewire is maintained at its insertion level with fluoroscopic control as the endoscope is removed. Over this wire a $140 \mathrm{~mL}$ nasogastric tube or enterolysis tube is passed and left in place. The guidewire should be sheathed, as this offers added stiffness. Fluoroscopic control is necessary (Figure 2). Because the wire is floppy, it can buckle or even slip back as the decompression tube is advanced. If the wire slips too far distally endoscopic reinsertion will be necessary.

Another method uses a fenestrated tygon overtube that is pushed out upon reaching the right colon (13), and the endoscope is then withdrawn. The passage of a decompression tube, attached by a short suture loop held by forceps through the channel and dropped off in the right colon, is another possibility $(14,15)$. Usually a double channel endoscope is required. There is the danger of pulling the tube back as the endoscope is withdrawn.

Does the endoscope have to reach the cecum? It is the author's opinion that the decompression tube in the region of the ascending colon and hepatic flexure should be adequate. The decompression tube is then attached to intermittent suction at $40 \mathrm{mmHg}$. The author currently irrigates with tap water $100 \mathrm{~mL}$ every 2 to $3 \mathrm{~h}$.

A flat plate is taken after the procedure to monitor colon size and tube placement. In all patients, control of cecal pseudo-obstruction takes place within $24 \mathrm{~h}$, and the tube may be withdrawn in three or four days, or sooner if peristalsis pushes it out.

At the author's institute, between 1984 and 1989,16 patients were treated with 17 decompressions. All patients were treated with conservative methods. When distension persisted or increased (all patients had cecal diameters of $12 \mathrm{~cm}$ or greater) endoscopic tube decompression was carried out (Table 3). All intubations were successful and no complication was encountered. All patients except one survived and left the hospital. The one patient died seven days after successful

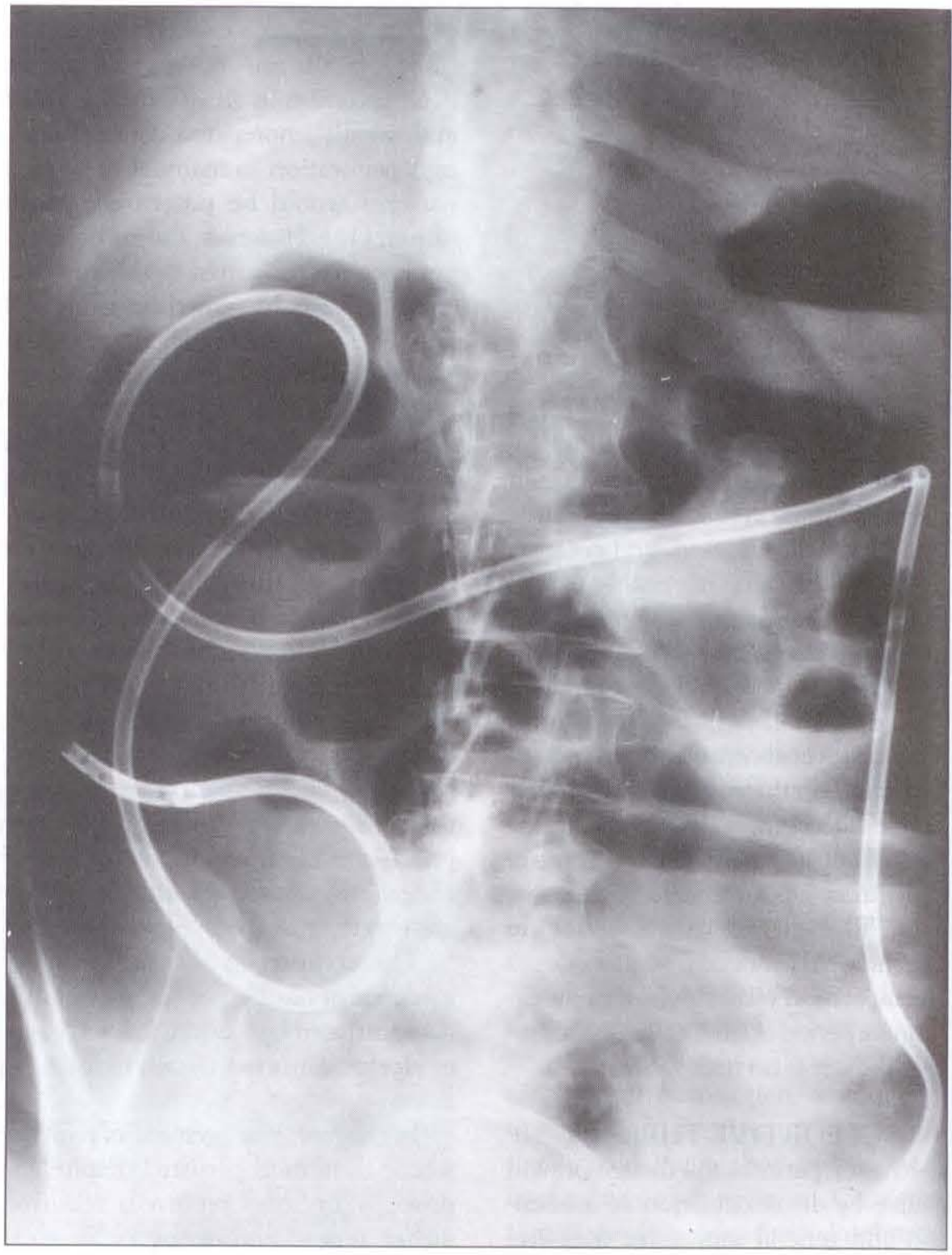

Figure 2) Radiopaque decompression tube placed in cecum

intubation, of massive pulmonary embolus. He was being treated for acute renal failure and sepsis. All cases with one exception were carried out under fluoroscopic control. One patient, a 24 year-old sailor with extensive third degree burns and sepsis, had a recurrence of ileus 10 days after successful tube decompression. His second intubation was also successful.

An alternative mode of decompression has recently been published (16). This describes the treatment of pseudoobstruction with an epidural block, and postulates that the problem is related to excessive sympathetic tone and that splanchnic sympathetic blockade by epidural anesthesia should be successful. Although this has the advantage of simplicity, only five of eight cases were successful. Pseudo-obstruction is a potentially fatal disorder in these critically ill patients. Early recognition with the institution of supportive means fol. lowed by colonoscopic decompression with tube placement should be success. ful in all cases.

Another condition in which endoscopic decompression is useful is narrowing of the distal colon developing into marked abdominal distension after colonoscopy. This distension may be precipitated by the antiperistaltic effects of analgesics or anticholinergics. 
In this situation the prompt passage of a nasogastric tube over an endoscopically placed, fluoroscopically monitored guidewire will result in quick relief from distension.

In cases of high grade obstruction, a slim gastroscope may be used. Under

\section{REFERENCES}

1. Ogilvie H. Large-intestine colic due to sympathetic deprivation. A new clinical syndrome. Br J Med 1948;2:671-3.

2. Wojtalik RS, Lindenauer SM, Kahn SS. Perforation of the colon associated with adynamic ileus. Am J Surg 1973;125:601-6.

3. Soreide O, Bjerkest T, Fossdal JE. Pseudoobstruction of the colon (Ogilvie's syndrome), a genuine clinical condition; review of the literature (1948-1975) and report of five cases. Dis Colon Rectum 1977;20:487-91.

4. Davis L, Lowman RM. Roentgen criteria of impending perforation of the cecum. Radiology 1957;68:542.

5. Freidman JD, Odland MD, Bulrick P. Experience with colonic volvulus. Dis Colon Rectum 1989;32:409-16.

6. Slayer A, Pannella V, Davies B, et al. Ogilvie's syndrome. Successful management without colonoscopy. Dig Dis Sci fluoroscopic control a guidewire is passed into the colon above and the endoscope withdrawn. The endoscopist may then dilate over the wire with a Savary-type boogie, and then pass a decompression tube above the narrowing. The colon above may then be ir-

1988;33:1391-6.

7. Kukora JS, Dent TL. Colonoscopic decompression of massive nonobstructive cecal dilation. Arch Surg 1977;112:512-7.

8. Nakhgevany KB. Colonoscopic decompression of the colon in patients with Ogilvie's syndrome. Am J Surg 1984;148:317-20.

9. Nivatvongs S, Vermeulen FD, Fang DT. Colonoscopic decompression of acute pseudo-obstruction of the colon. Ann Surg 1982;196:598-600.

10. Strodel WE, Nostrant TT, Eckhauser FE, Dent TL. Therapeutic and diagnostic colonoscopy in nonobstructive colonic dilation. Ann Surg 1983; 197:416-21.

11. Bode WE, Beart RW, Spencer RJ, Oulp CE, Wolff BG, Taylor BM. Colonoscopic decompression for acute pseudoobstruction of the colon (Ogilvie's syndrome). Am J Surg 1984;147:243-5. rigated and emptied. This method may also be used to decompress and prepare the colon for surgery by placing the tube through the tumour in a similar fashion, and irrigating and emptying the colon, thereby avoiding colostomy in a staged procedure.

12. Marcon N, Haber G, Kortan P. Colonoscopic decompression of colon in 3 patients with acute pseudoobstruction using a 10 French nasobiliary set. Gastrointest Endosc 1986;32:164.

13. Burke G, Shellito P. Treatment of recurrent colonic pseudo-obstruction by endoscopic placement of a fenestrated overtube. Dis Colon Rectum 1987;30:615-9.

14. Bernton E, Myers R, Reyna T. Pseudoobstruction of the colon: A case report including a new endoscopic treatment. Gastrointest Endosc 1982;28:90-2.

15. Groff W. Colonoscopic decompression and intubation of the cecum for Ogilvie's syndrome. Dis Colon Rectum 1983;26:503-6.

16. Lee JT, Taylor PM, Singleton BC, Epidural anaesthesia for acute pseudoobstruction of the colon (Ogilvie's syndrome). Dis Colon Rectum 1988;31:686-91. 


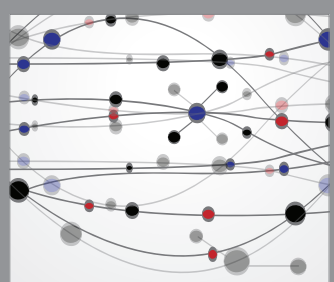

The Scientific World Journal
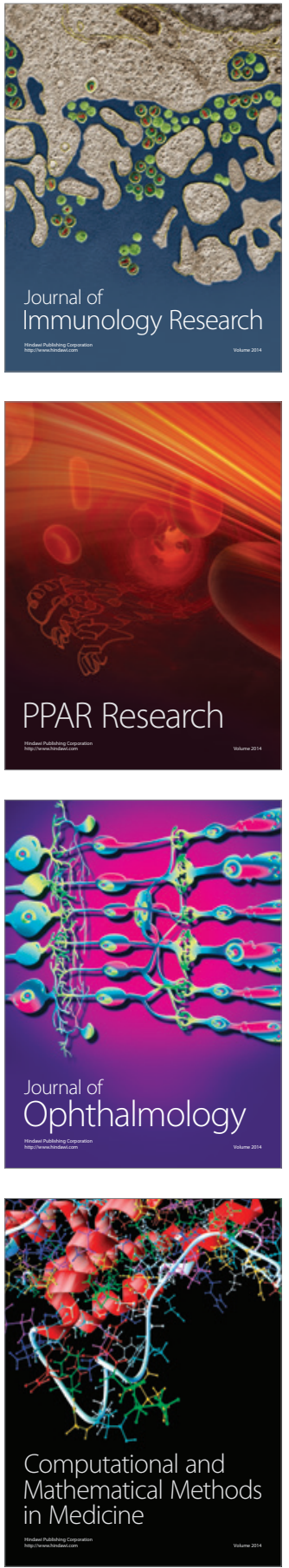

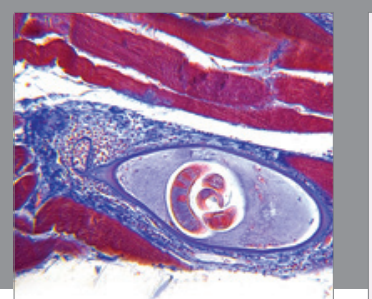

Gastroenterology Research and Practice

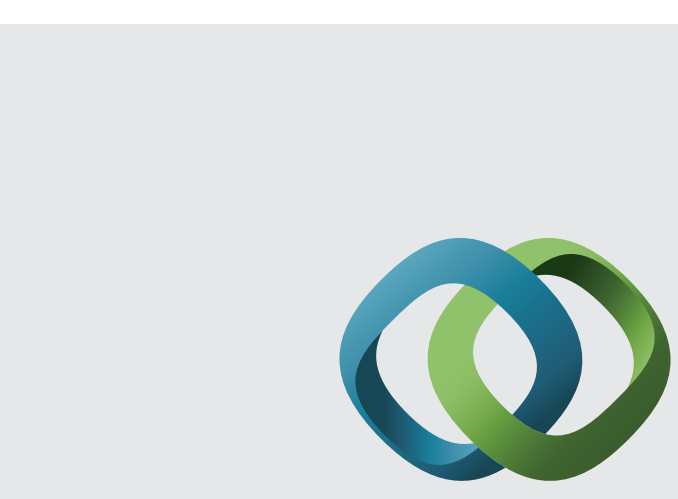

\section{Hindawi}

Submit your manuscripts at

http://www.hindawi.com
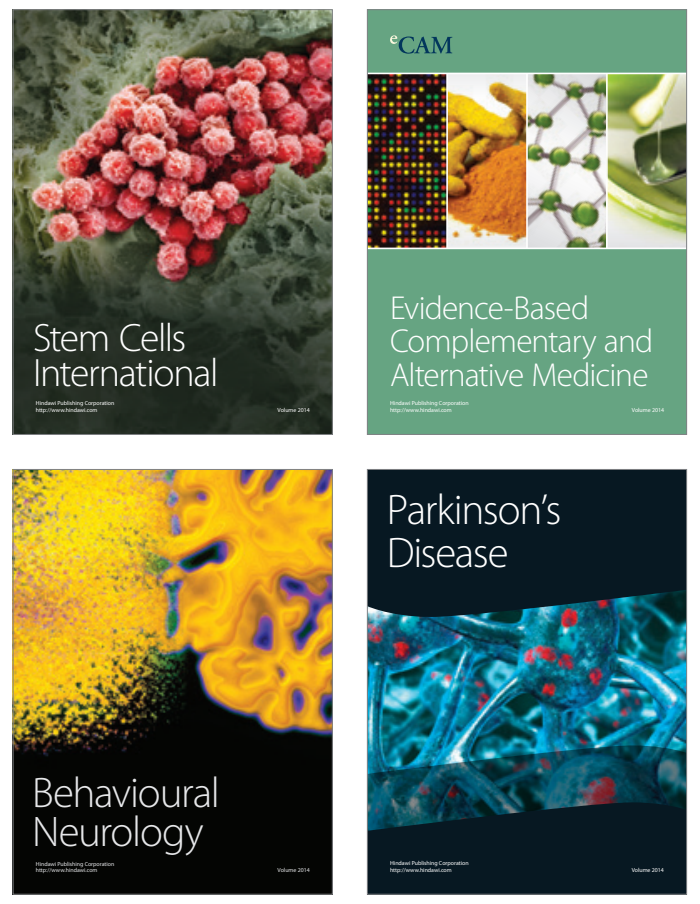
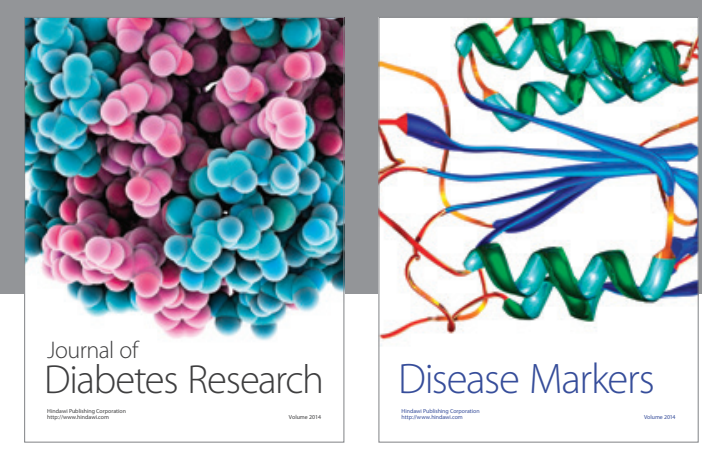

Disease Markers
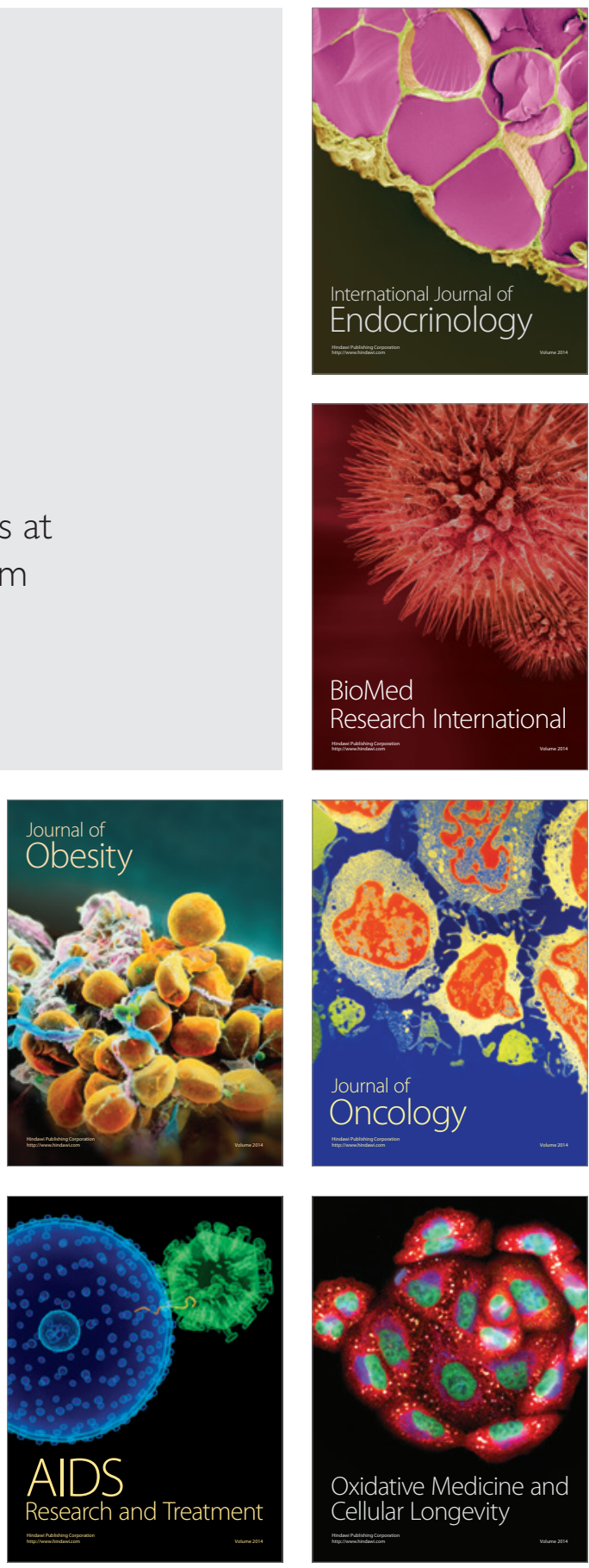